\title{
Further reductions in nonvertebral fracture rate with long-term denosumab treatment in the FREEDOM open-label extension and influence of hip bone mineral density after 3 years
}

\author{
S. Ferrari ${ }^{1}$ - J. D. Adachi ${ }^{2}$ - K. Lippuner ${ }^{3}$ - C. Zapalowski ${ }^{4}$ • P. D. Miller ${ }^{5}$. \\ J.-Y. Reginster ${ }^{6}$ • O. Törring ${ }^{7}$ • D. L. Kendler ${ }^{8}$ • N. S. Daizadeh ${ }^{4}$ • A. Wang ${ }^{4}$ • \\ C. D. O'Malley ${ }^{4}$ R. B. Wagman $^{4}$ - C. Libanati $^{4}$ - E. M. Lewiecki ${ }^{9}$
}

Received: 17 September 2014 / Accepted: 13 May 2015 /Published online: 12 June 2015

(C) The Author(s) 2015. This article is published with open access at Springerlink.com

\begin{abstract}
Summary Limited data exist on the efficacy of long-term therapies for osteoporosis. In osteoporotic postmenopausal women receiving denosumab for 7 years, nonvertebral fracture rates significantly decreased in years 4-7 versus years 1-3. This is the first demonstration of a further benefit on fracture outcomes with long-term therapy for osteoporosis.

Introduction This study aimed to evaluate whether denosumab treatment continued beyond 3 years is associated with a further reduction in nonvertebral fracture rates.

Methods Participants who completed the 3-year placebocontrolled Fracture REduction Evaluation of Denosumab in Osteoporosis every 6 Months (FREEDOM) study were invited to participate in an open-label extension. The present analysis includes 4,074 postmenopausal women with osteoporosis ( $n=2,343$ long-term; $n=1,731$ cross-over) who enrolled in the extension, missed $\leq 1$ dose during their first 3 years of denosumab treatment, and continued into the fourth year of
\end{abstract}

\section{S. Ferrari}

Serge.Ferrari@unige.ch

\footnotetext{
Geneva University Hospital, Geneva, Switzerland

McMaster University, Hamilton, ON, Canada

Bern University Hospital, Bern, Switzerland

Amgen Inc., Thousand Oaks, CA, USA

Colorado Center for Bone Research, Lakewood, CO, USA

University of Liège, Liège, Belgium

Karolinska Institutet, Södersjukhuset, Stockholm, Sweden

University of British Columbia, Vancouver, BC, Canada

New Mexico Clinical Research \& Osteoporosis Center, Albuquerque, NM, USA
}

treatment. Comparison of nonvertebral fracture rates during years 1-3 of denosumab with that of the fourth year and with the rate during years 4-7 was evaluated.

Results For the combined group, the nonvertebral fracture rate per 100 participant-years was 2.15 for the first 3 years of denosumab treatment (referent) and 1.36 in the fourth year (rate ratio $[R R]=0.64 ; 95 \%$ confidence interval $(\mathrm{CI})=0.48$ to $0.85, p=0.003)$. Comparable findings were observed in the groups separately and when nonvertebral fracture rates during years 1-3 were compared to years 4-7 in the longterm group $(\mathrm{RR}=0.79 ; 95 \% \mathrm{CI}=0.62$ to $1.00, p=0.046)$. Fracture rate reductions in year 4 were most prominent in subjects with persisting low hip bone mineral density (BMD). Conclusions Denosumab treatment beyond 3 years was associated with a further reduction in nonvertebral fracture rate that persisted through 7 years of continuous denosumab administration. The degree to which denosumab further reduces nonvertebral fracture risk appears influenced by the hip bone density achieved with initial therapy.

Keywords Denosumab · Fracture threshold · Hip bone mineral density $\cdot$ Long-term osteoporosis therapy •

Nonvertebral fracture · Treatment to goal

\section{Introduction}

Nonvertebral fractures, including hip fractures, represent $75 \%$ of all fragility fractures related to osteoporosis and are associated with significant morbidity and mortality [1-3]. In randomized placebo-controlled trials, nonvertebral fracture risk reduction in the range of $20 \%-30 \%$ over 3 years has been shown with denosumab and some (zoledronic acid, 
alendronate, risedronate), though not all, bisphosphonates [4-7].

Only a few studies evaluating the long-term efficacy of osteoporosis drugs are available. Bisphosphonate treatment extended beyond 3 years is generally associated with a plateau in hip bone mineral density (BMD) gains and fracture rates that remain comparable to those observed during the first 3 years; however, the number of subjects in these extension studies is limited, and evidence for further reduction in nonvertebral fracture rates with continued bisphosphonate therapy has not been reported [8-10]. Hence, while treatment with a bisphosphonate for more than 3 years may seem logical to prevent further deterioration of skeletal integrity in those who remain at high risk of fracture, the actual benefit of longterm antiresorptive (bisphosphonate) therapy has been questioned [11]. Larger studies are therefore needed to evaluate the fracture outcomes of long-term treatment for osteoporosis.

Denosumab (Prolia ${ }^{\circledR}$, Amgen Inc., Thousand Oaks, CA) is a fully human monoclonal antibody that binds with high affinity and specificity to RANK ligand and prevents the formation, function, and survival of osteoclasts [12, 13]. In the pivotal Fracture REduction Evaluation of Denosumab in $\underline{\text { Osteoporosis }}$ every 6 Months (FREEDOM) trial, denosumab reduced the incidence of vertebral, nonvertebral, and hip fractures over 3 years compared with placebo [7]. The effect of long-term denosumab treatment on fracture risk is being evaluated for a total of 10 years in an ongoing open-label FREEDOM extension. Six years of denosumab treatment produced continued increases in BMD, maintained the dynamic reduction in bone turnover markers, and was associated with a persistent low incidence of fractures, which was significantly lower than in a control group of modeled virtual twins $[14,15]$.

To further evaluate long-term fracture rates using each subject as her own control, we considered the subjects who enrolled in the FREEDOM extension, who missed no more than one denosumab injection during their first 3 years of denosumab treatment (in FREEDOM for those in the original denosumab group or in the extension for those in the original placebo group), and who continued into their fourth year of denosumab treatment. By this time, women in the original FREEDOM denosumab group (long-term subjects) had completed up to 7 years of treatment. We hypothesized that denosumab treatment continued beyond year 3 was associated with a further reduction in nonvertebral fracture rate compared with the first 3 years of treatment. Since previous reports documented that gains in hip BMD accounted for a large proportion of the effect of denosumab to reduce nonvertebral fractures [16], we also explored the relationship between hip BMD level attained at the end of 3 years of denosumab administration - as measured by femoral neck T-score-and subsequent nonvertebral fracture rates with longer-term denosumab administration.

\section{Materials and methods}

\section{Study design and procedures}

Both the FREEDOM (ClinicalTrials.gov: NCT00089791) and the extension (ClinicalTrials.gov: NCT00523341) study designs and main results have been previously described [7, $14,15]$. In summary, FREEDOM was a phase 3 , multinational, randomized, double-blind, placebo-controlled, 3-year study in postmenopausal women aged 60-90 years who had a lumbar spine or total hip T-score $<-2.5$ at either location and $\geq-4.0$ at both skeletal sites. Participants were randomly assigned to receive placebo or $60 \mathrm{mg}$ denosumab (Prolia ${ }^{\circledR}$, Amgen Inc., Thousand Oaks, CA) subcutaneously every 6 months for 3 years and were required to take calcium $(\geq 1 \mathrm{~g})$ and vitamin $\mathrm{D}(\geq 400 \mathrm{IU})$ daily. Women who completed the FREEDOM study (i.e., completed their 3-year visit, did not miss $>1$ dose of the investigational product [IP]) and did not receive other medications known to affect bone metabolism were invited to enroll in an extension study, during which all participants received open-label denosumab $60 \mathrm{mg}$ subcutaneously every 6 months with daily calcium and vitamin D [7]. Subjects who were randomized to denosumab in FREE DOM and continued denosumab treatment in the extension constitute the long-term group and subjects who were randomized to placebo treatment for 3 years and then started denosumab at the beginning of the extension constitute the cross-over group. By design, subjects were enrolled in the extension provided they had received at least five out of six denosumab or placebo doses over 3 years in FREEDOM. To ensure comparability between groups in the present analysis, we evaluated only those subjects in the cross-over group who received at least five out of six doses in their first 3 years of denosumab treatment and continued into their fourth year (the same criterion required for subjects originally assigned to denosumab to be eligible for and then enter the extension). The study protocol was approved by an institutional review board or ethics committee for each investigative site. Participants provided written informed consent.

Study visits occurred at baseline and every 6 months for the duration of the extension study. The study procedures were previously described [15] and followed the same collection rigor as during FREEDOM. All nonvertebral fractures required confirmation by diagnostic imaging or a radiologist's report and were adjudicated by a central vendor (Synarc), as previously described [7]. Hip BMD, as measured by dualenergy X-ray absorptiometry, was obtained in all subjects in FREEDOM, as previously reported $[7,17]$.

\section{Statistical analyses}

Analyses were implemented on subjects who enrolled in the FREEDOM extension, who missed $\leq 1$ dose of denosumab 
during their first 3 years of denosumab treatment, and who continued into their fourth year of denosumab treatment $(n=$ 2,343 long-term, $n=1,731$ cross-over). Yearly incremental estimates of the incidence of nonvertebral fractures were calculated using Kaplan-Meier methodology for both groups separately. Nonvertebral fracture rates per 100 participantyears during the first 3 years and the subsequent fourth year of denosumab treatment were computed and compared based on the rate ratio (year 4 versus years 1-3) in the long-term and cross-over groups separately and combined. For the long-term group, the nonvertebral fracture rate between years 4-7 of denosumab treatment also was computed and compared with the rate during the first 3 years (years 4 7 versus years $1-3$ ).

Nonvertebral fracture rates (per 100 participant-years), rate ratios, and $95 \%$ confidence intervals (CIs) were computed by generalized estimating equation Poisson regression. Rate ratios were adjusted for age, total hip T-score, weight, and history of nonvertebral fractures at the start of denosumab treatment (i.e., FREEDOM baseline for the long-term group and extension study baseline for the cross-over group). The treatment group variable was included in the model for the combined analysis.

Reductions in nonvertebral fracture rates during the fourth year versus years 1-3 of denosumab treatment were also evaluated in the combined group, based on the femoral neck T-score attained after the first 3 years of denosumab administration, for each of the clinically established and used densitometric categories (osteoporosis, low bone density, and normal) using the statistical methods described above.

\section{Results}

\section{Study participants}

Of 5,928 women eligible for the extension study, 4,550 (77\%) enrolled ( $n=2,343$ long-term; $n=2,207$ cross-over). Of these, 4,074 women ( $n=2,343$ long-term; $n=1,731$ cross-over) missed $\leq 1$ dose of denosumab in their first 3 years of denosumab treatment, continued into the fourth year of treatment, and were included in this analysis, representing up to 7 years of denosumab treatment in the long-term group and 4 years of denosumab treatment in the cross-over group (Fig. 1).

Participant characteristics at FREEDOM baseline for the cohort examined here were similar to those of the original FREEDOM population (Table 1). A larger proportion of cross-over participants were $\geq 75$ years old at the start of denosumab treatment, as the study had proceeded for 3 years from the original FREEDOM study baseline.

\section{Yearly incidences of nonvertebral fractures}

The yearly nonvertebral fracture incidences during the first 3 years of denosumab were similar in both the cross-over and long-term groups with an observed decrease in fracture incidence in year 4 for both groups (Fig. 2). Analysis of the long-term completers group $(N=1,867)$ demonstrated similar results with a decrease in fracture incidence between years 3 $(2.0 \%)$ and $4(1.2 \%)$. There was also a low incidence of yearafter-year hip fractures with long-term denosumab treatment in the FREEDOM extension of $0.3 \%$ or less every year after the initial 3 years of denosumab administration.

For the entire cohort of women receiving denosumab, the nonvertebral fracture rate per 100 participant-years was reduced by $36 \%$ (rate ratio $=0.64 ; p=0.003$ ) in year 4 compared with the first 3 years (Fig. 3a). A reduction of $49 \%$ (rate ratio= $0.51 ; p=0.005$ ) in the nonvertebral fracture rate for year 4 compared with years 1-3 was observed in the cross-over group (Fig. 3b). In the long-term group (i.e., those who have received up to 7 years of denosumab), the nonvertebral fracture rate was reduced by $25 \%$ (rate ratio $=0.75 ; p=0.127$ ) in year 4 compared with years 1-3; a similar reduction of $21 \%$ (rate ratio $=0.79 ; p=0.0046$ ) was observed when the nonvertebral fracture rate during years 4-7 was compared with years $1-3$ (Fig. 3c).

We next evaluated the influence of the BMD level attained after 3 years of denosumab treatment on the subsequent nonvertebral fracture risk reduction in the combined group. In subjects whose femoral neck T-scores remained $\leq-2.5$, a significant further reduction in nonvertebral fractures was observed in year 4 (rate ratio $=0.37 ; p=0.008$; Fig. 4). A further, but less pronounced, reduction in the nonvertebral fracture rate was also observed in subjects with T-scores $>-2.5$ and $<-1.0$ but not in subjects with T-scores $\geq-1.0$ (Fig. 4).

Similar observations were noted when total hip T-score was used instead of femoral neck T-score, with rate ratios of 0.85 $(0.46-1.60)$ for the $\leq-2.5$ group, $0.47(0.30-0.73)$ for the $>-2.5$ to $<-1.0$ group, and $1.22(0.67-2.25)$ for the $\geq-1.0$ group. The rate ratio of 0.85 did not reach significance which may have been the result of the small number of subjects $(N=$ $483)$ and the low number of fractures $(n=12)$ in this subgroup.

\section{Discussion}

With 4,074 participants, the cohort forming the basis of this report represents more than $50 \%$ of the original FREEDOM study subjects and is the largest extension study to date in the field of osteoporosis. Notably, despite aging of the subjects, the nonvertebral fracture rate during year 4 was significantly further decreased compared with the first 3 years of denosumab treatment. This pattern was observed in the overall cohort and similarly in both the subjects who received 
Fig. 1 Subject disposition in the FREEDOM study and its extension and the nonvertebral fracture analysis. Subjects included in the nonvertebral fracture analysis cohort enrolled in the FREEDOM extension, missed $\leq 1$ dose of denosumab during their first 3 years of denosumab treatment (whether during FREEDOM or the extension), and continued their fourth year of denosumab treatment. Gray boxes indicate subjects receiving denosumab. Asterisk: Two women who discontinued denosumab also entered the extension in the longterm denosumab group. $N V F X=$ nonvertebral fractures

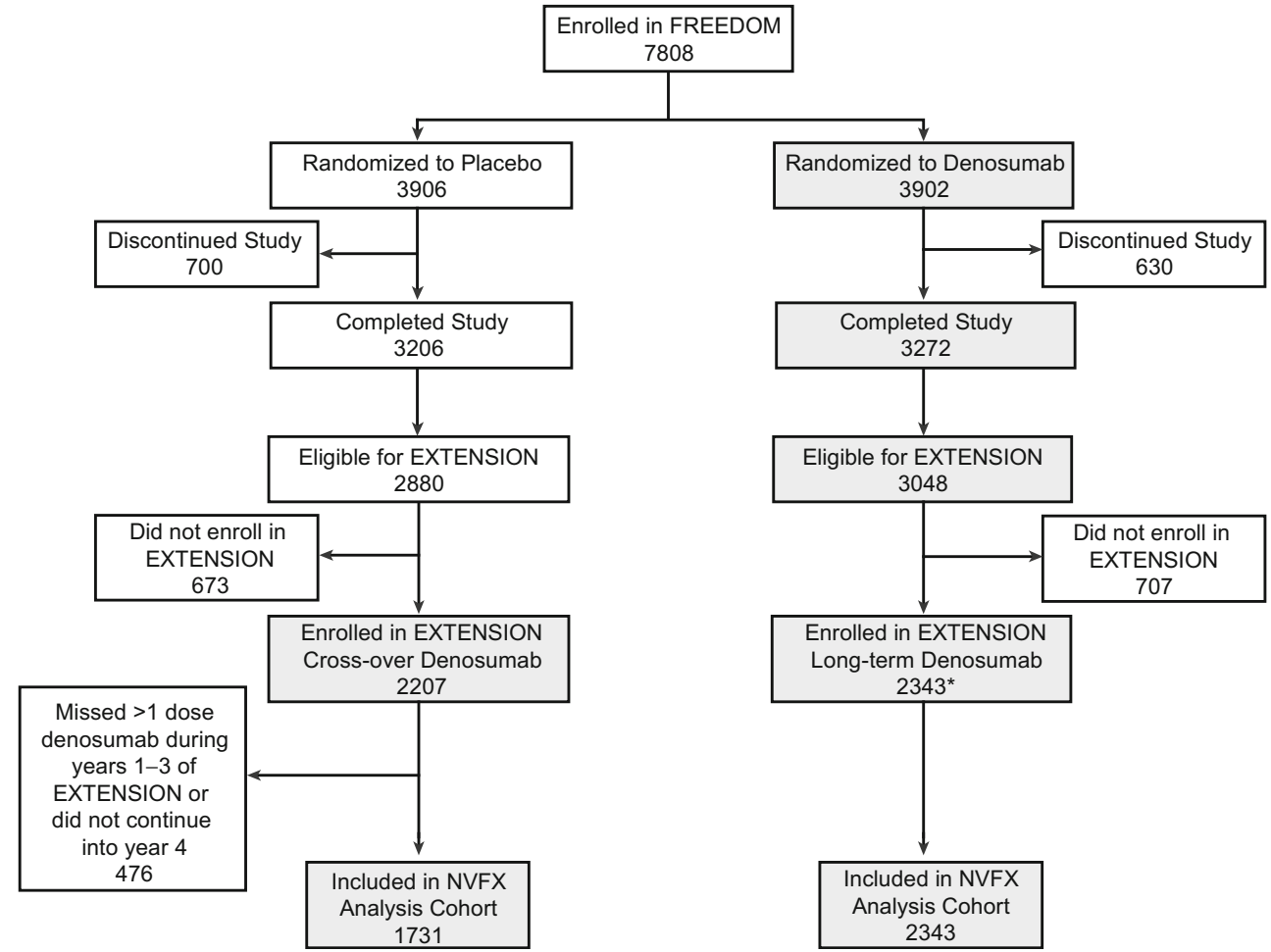

denosumab for 7 years, starting in FREEDOM, and for the group who started denosumab 3 years later, allowing a confirmatory evaluation. Moreover, the nonvertebral fracture rate was significantly lower in years 4-7 compared with years 1-3 in subjects who received denosumab for 7 years. This constitutes the first observation of a further benefit of an

Table 1 Baseline demographics

This study cohort

\begin{tabular}{cccc}
\hline $\begin{array}{l}\text { Full FREEDOM } \\
\text { population at baseline } \\
N=7,808\end{array}$ & $\begin{array}{l}\text { NVFX cohort at } \\
\text { FREEDOM baseline } \\
N=4,074\end{array}$ & $\begin{array}{l}\text { Long-term subjects at } \\
\text { FREEDOM baseline } \\
N=2,343\end{array}$ & $\begin{array}{l}\text { Cross-over subjects at } \\
\text { extension baseline } \\
N=1,731\end{array}$ \\
\hline $72.3(5.2)$ & $71.6(4.9)$ & $71.9(5.0)$ & $74.3(4.9)$ \\
$7,394(94.7)$ & $3,819(93.7)$ & $2,209(94.3)$ & $1,681(97.1)$ \\
$2,471(31.6)$ & $1,082(26.6)$ & $662(28.3)$ & $842(48.6)$ \\
$24.2(7.5)$ & $23.4(7.2)$ & $23.7(7.3)$ & $26.1(7.2)$ \\
$1,844(23.6)$ & $927(22.8)$ & $559(23.9)$ & $421(24.3)$ \\
$2,340(30.0)$ & $1,198(29.4)$ & $702(30.0)$ & $578(33.4)$ \\
$-2.83(0.69)$ & $-2.84(0.67)$ & $-2.83(0.67)$ & $-2.83(0.75)$ \\
$-1.90(0.81)$ & $-1.84(0.79)$ & $-1.85(0.79)$ & $-1.92(0.80)$ \\
$-2.16(0.72)$ & $-2.10(0.71)$ & $-2.11(0.71)$ & $-2.13(0.71)$ \\
$0.516(0.389,0.702)$ & $0.533(0.355,0.674)$ & $0.505(0.357,0.700)$ & $0.496(0.413,0.662)$ \\
$46.5(36.0,61.2)$ & $46.2(32.6,59.5)$ & $46.2(31.5,56.8)$ & $48.6(35.0,62.2)$ \\
\hline
\end{tabular}

Age groups $-n(\%)$

$\geq 65$ years

$\geq 75$ years

Years since menopause

Prevalent vertebral fractures $-n(\%)$

Prevalent nonvertebral fractures at age $\geq 55-n(\%)$

Lumbar spine T-score

Total hip T-score

Femoral neck T-score

$\mathrm{CTX}^{\mathrm{b}}$ (ng/mL) - median (Q1, Q3)

$\mathrm{P}_{\mathrm{NN}}{ }^{\mathrm{b}}(\mu \mathrm{g} / \mathrm{L})-\operatorname{median}(\mathrm{Q} 1, \mathrm{Q} 3)$
Age, years

\section{FREEDOM baseline $N=4,074$}

FREEDOM baseline ${ }^{\mathrm{a}}$ $N=2,343$
Cross-over subjects at extension baseline ${ }^{\mathrm{a}}$

$74.3(4.9)$

$681(97.1)$

$842(48.6)$

$26.1(7.2)$

$421(24.3)$

578 (33.4)

$-2.83(0.75)$

$-1.92(0.80)$

$496(0.413,0.662)$

Data are means with standard deviations unless otherwise noted

$B M D$ bone mineral density, $C T X$ C-terminal telopeptide of type 1 collagen, $N$ number of participants enrolled in the extension study, $N V F X$ nonvertebral fractures, $P 1 N P$ procollagen type $1 \mathrm{~N}$-terminal propeptide

${ }^{\text {a }}$ Represents characteristics at the time of denosumab treatment start

${ }^{\mathrm{b}}$ Data are from participants who were included in the bone turnover marker substudy 
Fig. 2 Yearly incidence of nonvertebral fractures in the post hoc analysis participants. a Yearly incidence of nonvertebral fractures through 4 years of denosumab treatment for the cross-over group. b Yearly incidence of nonvertebral fractures through 7 years for the long-term denosumab group in the long-term participants. Percentages for nonvertebral fractures are Kaplan-Meier estimates. $D M A b=$ denosumab, $n$ $=$ number of subjects who have $\geq 1$ nonvertebral fracture
a

Cross-over
DMAb
Treatment

b
b
Long-term
DMAb
Treatment

EXTENSION

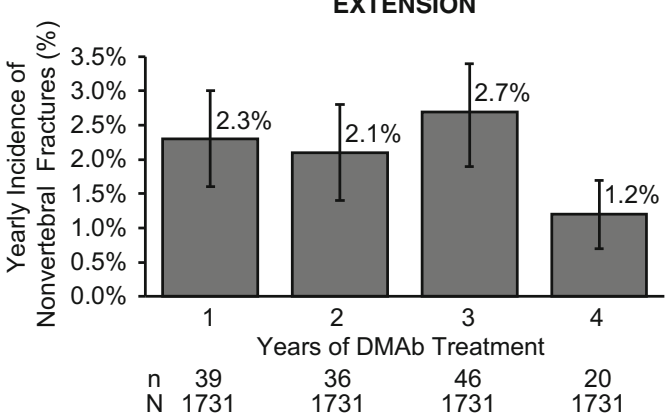

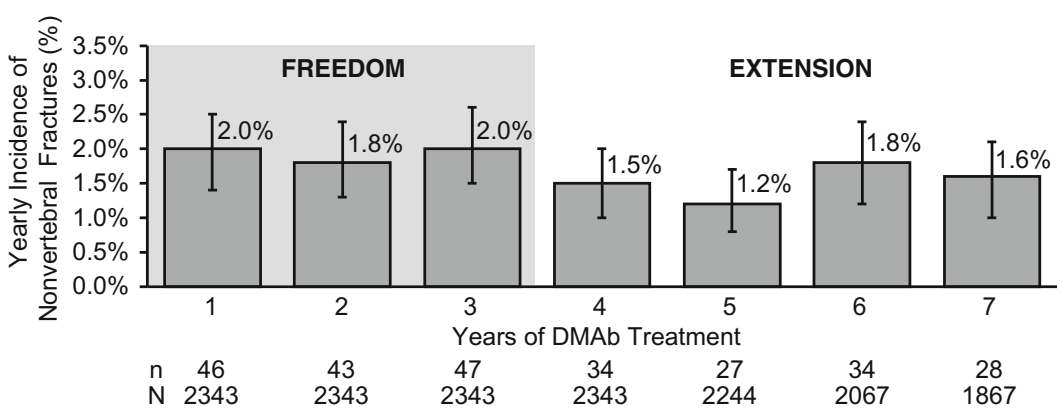

antiresorptive therapy on nonvertebral fractures beyond 3 years of initial administration.

Extension studies with other antiresorptive drugs have not shown increases in hip BMD or incremental reductions in nonvertebral fracture rates beyond those observed in the first few years of treatment. For example, results from the Vertebral Efficacy With Risedronate Therapy-North America (VERTNA) trial with risedronate found no significant reduction in the rate of nonvertebral fractures in 2 years of additional risedronate treatment versus the first 3 years of treatment [10]. Similarly, the Fracture Intervention Trial Long-Term Extension (FLEX) study did not find a significant difference between the cumulative risk of nonvertebral fractures for postmenopausal women continuing alendronate for 5 more years beyond the initial 5 years of treatment $[9,18]$. More recently, the extension of the Health Outcomes and Reduced Incidence with Zoledronic Acid Once Yearly-Pivotal Fracture Trial (HORIZON-PFT) documented that 6 years of treatment with zoledronic acid resulted in no significant differences in nonvertebral fracture incidence compared with the first 3 years of treatment nor compared with placebo during the extension [8]. Although nonvertebral fracture rates in the extension studies with alendronate and zoledronic acid were reported for those women who entered the extension and therefore were applicable to only a subset of those enrolled in the 3-year pivotal studies, the rates of nonvertebral fracture in the first 3 years were similar to those seen through the completion of both extension studies [4-6, 19]. These extension studies were not adequately powered for nonvertebral fracture endpoints.

Data on nonvertebral fractures with long-term denosumab treatment appear to show a different pattern. Indeed, our analyses suggest that continuing denosumab treatment beyond 3 years reduces the nonvertebral fracture rate compared with the first 3 years of treatment. Denosumab effects that may contribute to this distinctive observation include documented rapid, marked, and sustained reductions in bone resorption markers following each denosumab dose, and progressive gains in BMD reported with up to 8 years of continuous denosumab administration, decreases in cortical porosity with corresponding increases in cortical bone mass, and increases in cortical and trabecular strength as detailed with denosumab in clinical and animal studies [14, 20-26].

In our study, the mean age of women starting denosumab was 72 years for the long-term group and 74 years for those starting denosumab in the cross-over extension group, populations in which one would expect an increasing risk of fracture over time due to the skeletal deterioration associated with aging $[27,28]$. Yet, long-term treatment with denosumab was instead associated with further nonvertebral fracture risk reduction over that documented during the first 3 years of therapy. Importantly, the pattern of decrease was similar in both groups, despite the older age of the women in the cross-over group.

The risk of a fracture is dependent on the amount and distribution of the bone mass at the skeletal site as well as the frequency and characteristics of the associated trauma, as exemplified by the variable forces that are associated with each fall [29]. There are no biological reasons to suspect an effect of denosumab on fall risk or characteristics of falling, whereas continued BMD increases are observed over time with denosumab treatment. Thus, it is plausible that the further reduction in fractures observed after 3 years of denosumab administration could be attributed to a larger proportion of 
Fig. 3 Nonvertebral fracture rate ratios. a All denosumab-treated participants. b Cross-over participants. c Long-term participants. $N=$ number of subjects who completed FREE DOM (i.e., completed their 3-year visit and did not discontinue IP), missed $\leq 1$ dose of IP in FREE DOM, and who enrolled in the extension. In addition, cross-over subjects completed 3 years of the extension and missed $\leq 1$ dose of denosumab during the first 3 years of the extension. Fracture rates and rate ratios were obtained using generalized estimating equation Poisson models; fracture rates are per 100 participantyears. Rate ratios relative to the first 3 years of denosumab treatment were adjusted for age, total hip T-score, weight, and history of nonvertebral fracture. In addition, the treatment group variable was included in the model for the combined analysis only
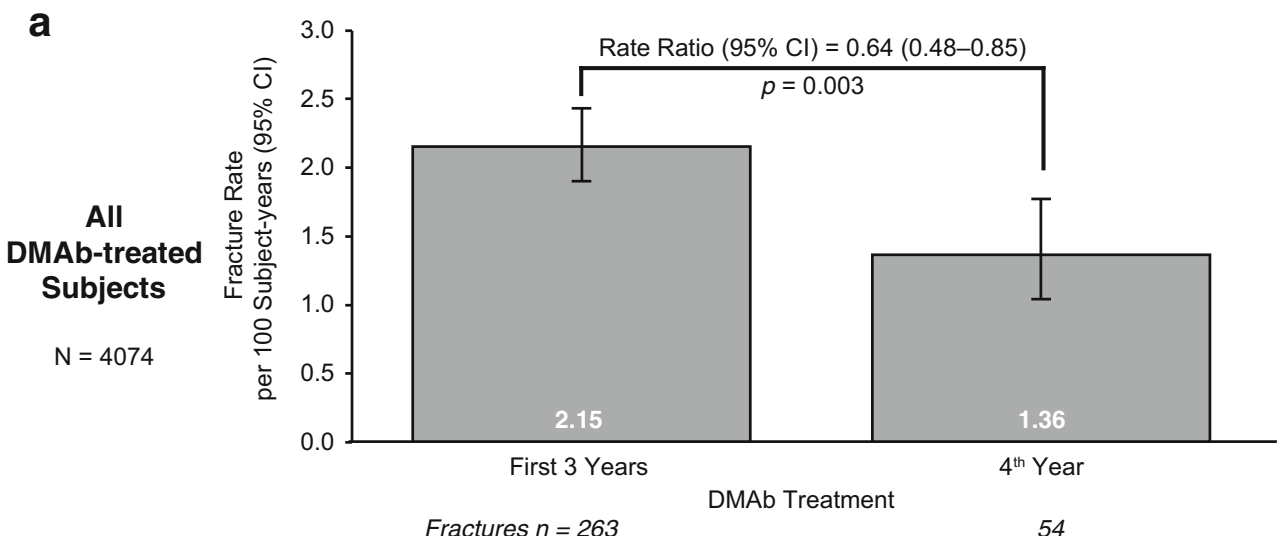
b

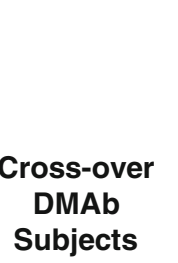

$N=1731$

C

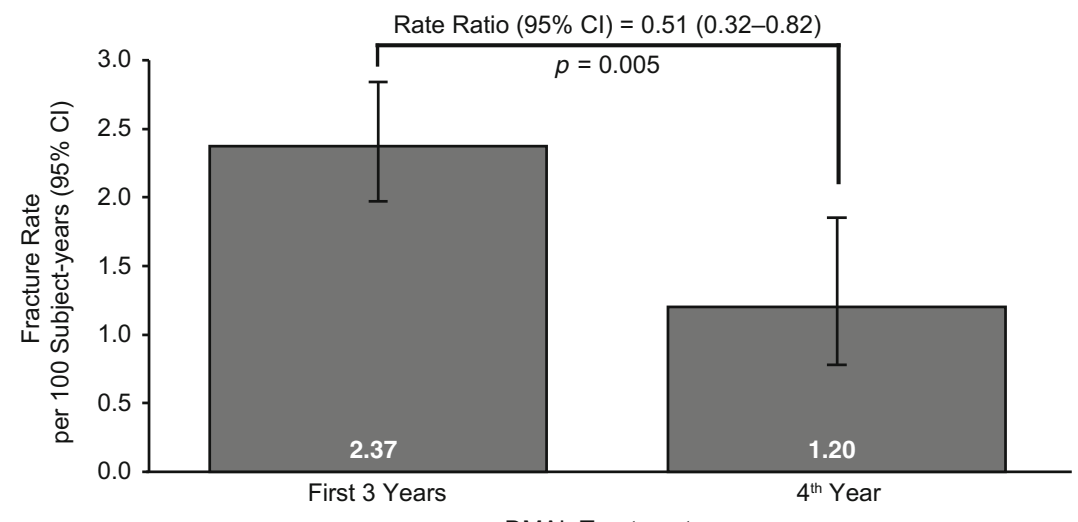

Fractures $n=123$

DMAb Treatment

20

Rate Ratio $(95 \% \mathrm{Cl})=0.79(0.62-1.00)$

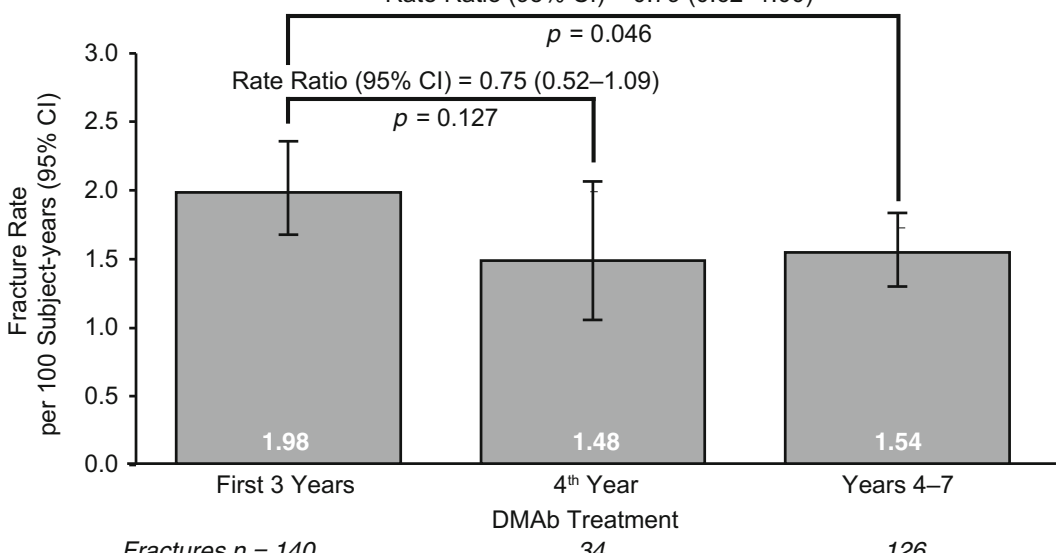

Fractures $n=140$ subjects achieving a BMD value needed to reduce the factor of risk for fracture [30].

Acknowledging that factors such as actual change in BMD, body mass index, bone turnover rate, genetic predisposition, and frailty also contribute to fracture risk in the individual patient, our analysis found that fracture reductions observed in year 4 and beyond were correlated with hip BMD attained after 3 years of denosumab. Those subgroups of subjects for whom BMD remained low after 3 years of denosumab treatment had a documented additional benefit, whereas additional nonvertebral fracture risk reductions were not observed in those who had attained a normal bone density level. One explanation may be that there is a densitometric inflection point above which further gains in bone density are no longer associated with corresponding additional fracture reductions. Our data suggest that this BMD level lies between a T-score of -2.5 and -1.0 , a concept also substantiated by recent work combining BMD and femoral strength by finite element analysis [31]. These data also support the concept that further fracture risk reduction may be related to continued increases in hip BMD; in the original FREEDOM trial, the change in hip BMD explained a considerable amount of the reduction in nonvertebral fracture risk [16]. 


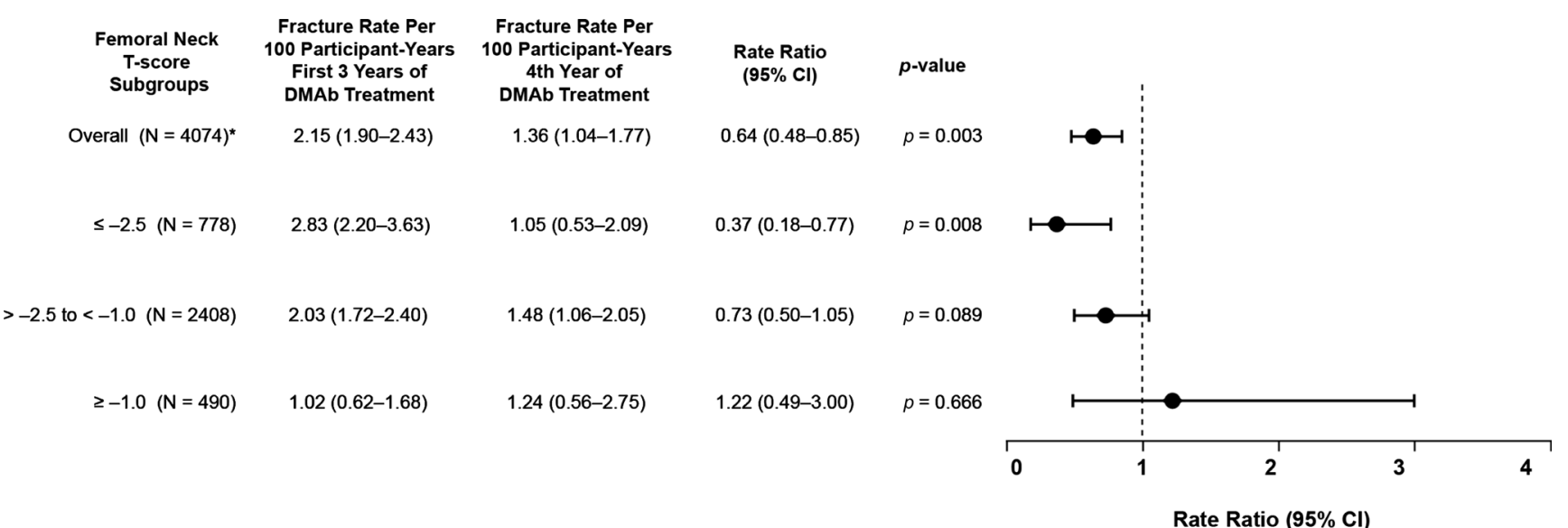

Fig. 4 Effect of femoral neck T-score on nonvertebral fracture rates in year 4 compared with years 1-3. Circles are rate ratios and lines indicate $95 \%$ confidence intervals for the comparison of nonvertebral fracture rate per 100 participant-years for years $1-3$ of denosumab treatment versus year 4 in the combined cohort overall and for subgroups determined by femoral neck T-score at the end of 3 years of denosumab treatment. Asterisk: 398 subjects did not have BMD data available at the end of year 3 of denosumab treatment
Our study has a number of strengths including the following: (i) it has the largest population in an ongoing extension study with a planned robust assessment of fracture as an outcome; (ii) the decrease in fracture observed with the long-term group was replicated in the cross-over group that was 3 years older at the time of starting denosumab and observed within the extension phase of the study mitigating the possible impact of a cohort bias; and (iii) persistent low fracture rates were observed through year 7 .

Our study also has limitations, namely that, as is the case for all extension studies, the original population may differ from the cohort of subjects enrolled in the extension study (potential selection bias) and the post hoc nature of the analyses. In particular, by design, subjects were enrolled in the extension provided they had received at least five out of six denosumab or placebo doses over 3 years in FREEDOM and at least five out of six denosumab doses in the first 3 years of the extension for the cross-over group. Hence, the further fracture risk reductions observed in year 4 of therapy and beyond may not have been observed among subjects with less than optimal persistence. In addition, while this extension enrolled a significant number of subjects, the small number of events and the year-by-year variability remind us that some degree of caution should exist in the interpretation of the data. Attrition of subjects at high risk during the extension could also influence the results; however, this is unlikely because (a) the proportion of patients who sustained a fracture and remained on study increased over time, and (b) the conclusions remain valid even if we assume a fracture rate in those who discontinued or died that is double that observed in the remaining subjects [32]. Finally, these analyses cannot substitute for the results of a randomized placebo-controlled study. The need for an open-label extension study was predicated on ethical concerns for continuing placebo treatment after demonstration of denosumab anti-fracture efficacy in the FREEDOM parent study.

In summary, in the ongoing extension to the FREEDOM study, nonvertebral fracture rates were reduced during year 4 and beyond as compared with the first 3 years of denosumab administration, a period for which robust fracture reduction is already established. This observation appears distinctive to denosumab administration for patients with osteoporosis and who remain at risk for fracture based on bone densitometry. Further confirmation of the benefits for nonvertebral fracture protection in years beyond the fourth, or with regard to other clinical parameters, awaits completion of all 10 years of the FREEDOM extension study.

Acknowledgments The authors thank the FREEDOM extension trial investigators and participants. Funding for the study was provided by Amgen Inc. and GSK. Representatives of Amgen Inc. were responsible for the design and conduct of the study and coordination of data collection and management. Study investigators collected and managed data from their individual study sites. Two authors from Amgen Inc. (Nadia Daizadeh and Andrea Wang) conducted the analysis of the data; all authors were involved in the interpretation of the data. The manuscript was drafted by the authors with medical writing support from Holly Brenza Zoog, PhD, Erica Rockabrand, PhD, and Michelle N Bradley, PhD, of Amgen Inc., and Steven Tresker of Cactus Communications Inc., funded by Amgen Inc. Amgen Inc. and GSK reviewed a near final manuscript draft. All authors made the decision to submit the manuscript for publication. Serge Ferrari and Nadia Daizadeh had full access to all the data in the study and take responsibility for the integrity of the data and the accuracy of the data analysis.

Conflicts of interest Dr. Ferrari reports grants and personal fees from Amgen, grants and personal fees from MSD, personal fees from Eli Lilly, and personal fees from GSK.

Dr. Adachi reports grants and personal fees from Amgen, grants and personal fees from Eli Lilly, grants and personal fees from Merck, grants and personal fees from Novartis, and personal fees from Warner Chilcott, outside the submitted work. 
Dr. Lippuner reports participating on advisory boards for Amgen, Lilly, MSD, Takeda, and UCB.

Dr. Zapalowski, Dr. Daizadeh, Ms. Wang, Dr. O’Malley, Dr. Wagman, and Dr. Libanati report being employees of and owning stock or stock options in Amgen Inc.

Dr. Miller reports participating on advisory boards for Amgen Inc., Lilly, and Merck; expert witness or consultant in litigation for commercial entities for Novartis; received honoraria or royalties from Warner Chilcott; and received research grants from Amgen Inc., Lilly, Merck, and Radius.

Dr. Reginster reports personal fees from Servier, Novartis, Negma, Lilly, Wyeth, Amgen, GlaxoSmithKline, Roche, Merckle, NycomedTakeda, NPS, IBSA-Genevrier, Theramex, UCB, and Asahi Kasei, grants from Bristol Myers Squibb, Merck Sharp \& Dohme, Rottapharm, Teva, Lilly, Novartis, Roche, GlaxoSmithKline, Amgen, Servier, Pfizer, Theramex, Danone, Organon, Therabel, Boehringer, Chiltern, and Galapagos, and personal fees from Merck Sharp \& Dohme, Lilly, Rottapharm, IBSA, Genevrier, Novartis, Servier, Roche, GlaxoSmithKline, Teijin, Teva, Ebewee Pharma, Zodiac, Analis, Theramex, Nycomed, Novo-Nordisk, Merckle, Danone, and Will PharmaĐ outside the submitted work.

Dr. Törring reports other from Amgen, personal fees from Amgen, personal fees from GSK, personal fees from Takeda, and personal fees from Lilly, outside the submitted work.

Dr. Kendler reports consulting fees from Merck; participated on advisory boards for Amgen Inc., Eli Lilly, Novartis, and Pfizer; received honoraria or royalties from Amgen Inc., Eli Lilly, Novartis, Pfizer, and Warner Chilcott; and received research grants from Amgen Inc., Eli Lilly, GSK, J\&J, Novartis, and Pfizer.

Dr. Lewiecki reports grants from Amgen, Eli Lilly, and Merck; received consulting fees from AgNovos Healthcare, Alexion, Amgen, Eli Lilly, Merck, Radius Health, and Theranova; and is an association board member for the National Osteoporosis Foundation and the International Society for Clinical Densitometry.

Ethical approval All procedures performed in this study were in accordance with the ethical standards of the institutional review boards and or ethics committees and with the Declaration of Helsinki. The protocol and consent forms were approved by the institutional review boards and/ or the ethics committees at each participating study site.

Open AccessThis article is distributed under the terms of the Creative Commons Attribution-NonCommercial 4.0 International License (http:// creativecommons.org/licenses/by-nc/4.0/), which permits any noncommercial use, distribution, and reproduction in any medium, provided you give appropriate credit to the original author(s) and the source, provide a link to the Creative Commons license, and indicate if changes were made.

\section{References}

1. Abrahamsen B, van Staa T, Ariely R, Olson M, Cooper C (2009) Excess mortality following hip fracture: a systematic epidemiological review. Osteoporos Int 20:1633-1650

2. Bliuc D, Nguyen ND, Milch VE, Nguyen TV, Eisman JA, Center JR (2009) Mortality risk associated with low-trauma osteoporotic fracture and subsequent fracture in men and women. JAMA 301: 513-521

3. Bliuc D, Nguyen TV, Eisman JA, Center JR (2014) The impact of non-hip non-vertebral fractures in elderly women and men. J Clin Endocrinol Metab 99:415-423

4. Black DM, Cummings SR, Karpf DB, Cauley JA, Thompson DE, Nevitt MC, Bauer DC, Genant HK, Haskell WL, Marcus R, Ott
SM, Torner JC, Quandt SA, Reiss TF, Ensrud KE (1996) Randomised trial of effect of alendronate on risk of fracture in women with existing vertebral fractures. Fracture Intervention Trial Research Group. Lancet 348:1535-1541

5. Black DM, Delmas PD, Eastell R, Reid IR, Boonen S, Cauley JA, Cosman F, Lakatos P, Leung PC, Man Z, Mautalen C, Mesenbrink $\mathrm{P}, \mathrm{Hu} \mathrm{H}$, Caminis J, Tong K, Rosario-Jansen T, Krasnow J, Hue TF, Sellmeyer D, Eriksen EF, Cummings SR, Trial HPF (2007) Onceyearly zoledronic acid for treatment of postmenopausal osteoporosis. N Engl J Med 356:1809-1822

6. Cummings SR, Black DM, Thompson DE, Applegate WB, BarrettConnor E, Musliner TA, Palermo L, Prineas R, Rubin SM, Scott JC, Vogt T, Wallace R, Yates AJ, LaCroix AZ (1998) Effect of alendronate on risk of fracture in women with low bone density but without vertebral fractures: results from the Fracture Intervention Trial. JAMA 280:2077-2082

7. Cummings SR, San Martin J, McClung MR, Siris ES, Eastell R, Reid IR, Delmas P, Zoog HB, Austin M, Wang A, Kutilek S, Adami S, Zanchetta J, Libanati C, Siddhanti S, Christiansen C, Trial F (2009) Denosumab for prevention of fractures in postmenopausal women with osteoporosis. N Engl J Med 361:756-765

8. Black DM, Reid IR, Boonen S, Bucci-Rechtweg C, Cauley JA, Cosman F, Cummings SR, Hue TF, Lippuner K, Lakatos P, Leung PC, Man Z, Martinez RL, Tan M, Ruzycky ME, Su G, Eastell R (2012) The effect of 3 versus 6 years of zoledronic acid treatment of osteoporosis: a randomized extension to the HORIZON-Pivotal Fracture Trial (PFT). J Bone Miner Res 27: 243-254

9. Black DM, Schwartz AV, Ensrud KE, Cauley JA, Levis S, Quandt SA, Satterfield S, Wallace RB, Bauer DC, Palermo L, Wehren LE, Lombardi A, Santora AC, Cummings SR, Group FR (2006) Effects of continuing or stopping alendronate after 5 years of treatment: the Fracture Intervention Trial Long-term Extension (FLEX): a randomized trial. JAMA 296:2927-2938

10. Sorensen OH, Crawford GM, Mulder H, Hosking DJ, Gennari C, Mellstrom D, Pack S, Wenderoth D, Cooper C, Reginster JY (2003) Long-term efficacy of risedronate: a 5-year placebo-controlled clinical experience. Bone 32:120-126

11. Whitaker M, Guo J, Kehoe T, Benson G (2012) Bisphosphonates for osteoporosis - where do we go from here? N Engl J Med 366: 2048-2051

12. Cavalli L, Brandi ML (2012) Targeted approaches in the treatment of osteoporosis: differential mechanism of action of denosumab and clinical utility. Ther Clin Risk Manag 8:253-266

13. McClung MR (2013) Denosumab. In: Rosen CJ (ed) Primer on the metabolic bone diseases and disorders of mineral metabolism. John Wiley \& Sons, pp 420-424

14. Bone HG, Chapurlat R, Brandi ML, Brown JP, Czerwinski E, Krieg MA, Man Z, Mellstrom D, Radominski SC, Reginster JY, Resch H, Roman Ivorra JA, Roux C, Vittinghoff E, Daizadeh NS, Wang A, Bradley MN, Franchimont N, Geller ML, Wagman RB, Cummings SR, Papapoulos S (2013) The effect of three or six years of denosumab exposure in women with postmenopausal osteoporosis: results from the FREEDOM extension. J Clin Endocrinol Metab 98:4483-4492

15. Papapoulos S, Chapurlat R, Libanati C, Brandi ML, Brown JP, Czerwinski E, Krieg MA, Man Z, Mellstrom D, Radominski SC, Reginster JY, Resch H, Roman Ivorra JA, Roux C, Vittinghoff E, Austin M, Daizadeh N, Bradley MN, Grauer A, Cummings SR, Bone HG (2012) Five years of denosumab exposure in women with postmenopausal osteoporosis: results from the first two years of the FREEDOM extension. J Bone Miner Res 27:694-701

16. Austin M, Yang YC, Vittinghoff E, Adami S, Boonen S, Bauer DC, Bianchi G, Bolognese MA, Christiansen C, Eastell R, Grauer A, Hawkins F, Kendler DL, Oliveri B, McClung MR, Reid IR, Siris ES, Zanchetta J, Zerbini CA, Libanati C, Cummings SR, Trial F 
(2012) Relationship between bone mineral density changes with denosumab treatment and risk reduction for vertebral and nonvertebral fractures. J Bone Miner Res 27:687-693

17. Bolognese MA, Teglbjaerg CS, Zanchetta JR, Lippuner K, McClung MR, Brandi ML, Hoiseth A, Lakatos P, Moffett AH, Lorenc RS, Wang A, Libanati C (2013) Denosumab significantly increases DXA BMD at both trabecular and cortical sites: results from the FREEDOM study. J Clin Densitom 16:147-153

18. Bone HG, Hosking D, Devogelaer JP, Tucci JR, Emkey RD, Tonino RP, Rodriguez-Portales JA, Downs RW, Gupta J, Santora AC, Liberman UA, Alendronate Phase IIIOTSG (2004) Ten years' experience with alendronate for osteoporosis in postmenopausal women. N Engl J Med 350:1189-1199

19. Ensrud KE, Barrett-Connor EL, Schwartz A, Santora AC, Bauer DC, Suryawanshi S, Feldstein A, Haskell WL, Hochberg MC, Torner JC, Lombardi A, Black DM, Fracture Intervention Trial Long-Term Extension Research G (2004) Randomized trial of effect of alendronate continuation versus discontinuation in women with low BMD: results from the Fracture Intervention Trial longterm extension. J Bone Miner Res 19:1259-1269

20. Kostenuik PJ, Smith SY, Jolette J, Schroeder J, Pyrah I, Ominsky MS (2011) Decreased bone remodeling and porosity are associated with improved bone strength in ovariectomized cynomolgus monkeys treated with denosumab, a fully human RANKL antibody. Bone 49:151-161

21. Ominsky MS, Stouch B, Schroeder J, Pyrah I, Stolina M, Smith SY, Kostenuik PJ (2011) Denosumab, a fully human RANKL antibody, reduced bone turnover markers and increased trabecular and cortical bone mass, density, and strength in ovariectomized cynomolgus monkeys. Bone 49:162-173

22. Zebaze RM, Libanati C, Austin M, Ghasem-Zadeh A, Hanley DA, Zanchetta JR, Thomas T, Boutroy S, Bogado CE, Bilezikian JP, Seeman E (2014) Differing effects of denosumab and alendronate on cortical and trabecular bone. Bone 59:173-179

23. Iolascon G, Napolano R, Gioia M, Moretti A, Riccio I, Gimigliano F (2013) The contribution of cortical and trabecular tissues to bone strength: insights from denosumab studies. Clin Cases Miner Bone Metab 10:47-51
24. McClung MR, Lewiecki EM, Geller ML, Bolognese MA, Peacock M, Weinstein RL, Ding B, Rockabrand E, Wagman RB, Miller PD (2013) Effect of denosumab on bone mineral density and biochemical markers of bone turnover: 8 -year results of a phase 2 clinical trial. Osteoporos Int 24:227-235

25. Genant HK, Engelke K, Hanley DA, Brown JP, Omizo M, Bone HG, Kivitz AJ, Fuerst T, Wang H, Austin M, Libanati C (2010) Denosumab improves density and strength parameters as measured by QCT of the radius in postmenopausal women with low bone mineral density. Bone 47:131-139

26. Simon JA, Recknor C, Moffett AH Jr, Adachi JD, Franek E, Lewiecki EM, McClung MR, Mautalen CA, Ragi-Eis S, Nicholson GC, Muschitz C, Nuti R, Torring O, Wang A, Libanati C (2013) Impact of denosumab on the peripheral skeleton of postmenopausal women with osteoporosis: bone density, mass, and strength of the radius, and wrist fracture. Menopause 20:130-137

27. Kanis JA, Johnell O, Oden A, Dawson A, De Laet C, Jonsson B (2001) Ten year probabilities of osteoporotic fractures according to BMD and diagnostic thresholds. Osteoporos Int 12:989-995

28. Krege JH, Wan X, Lentle BC, Berger C, Langsetmo L, Adachi JD, Prior JC, Tenenhouse A, Brown JP, Kreiger N, Olszynski WP, Josse RG, Goltzman D, CaMos Research G (2013) Fracture risk prediction: importance of age, BMD and spine fracture status. Bonekey Rep 2:404

29. Bouxsein M (2006) Biomechanics of osteoporotic fractures. Clin Rev Bone Miner Metab 4:143-153

30. Keaveny TM, Bouxsein ML (2008) Theoretical implications of the biomechanical fracture threshold. J Bone Miner Res 23:1541-1547

31. Kopperdahl DL, Aspelund T, Hoffmann PF, Sigurdsson S, Siggeirsdottir K, Harris TB, Gudnason V, Keaveny TM (2014) Assessment of incident spine and hip fractures in women and men using finite element analysis of CT scans. J Bone Miner Res 29:570-580

32. Adachi JD, Ho PR, Lin CJF, Bolognese MA, Bone HG, Hadji P, Papapoulos S, Recknor C, Daizadeh NS, Dakin P, Wagman RB, Ferrari S (2014) Evolution of subject characteristics in FREEDOM and its extension for up to 8 years. J Bone Miner Res 29:S470 